\title{
BIENESTAR UNIVERSITARIO, UN CONCEPTO DE FORMACIÓN PARA LA VIDA
}

Sandra Yanneth Cely C.*

"El bien mas grande que podemos hacer a otros no es compartir con ellos nuestra riqueza, sino ayudarles a descubrir la propia"

B.Disraeli.

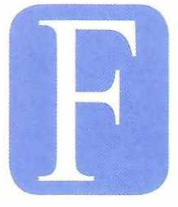

ormar para la vida desde el bienestar universitario significa que su quehacer se fundamenta en la creación de espacios y momentos para el desarrollo personal de aquellos que integran la comunidad universitaria, creando desde allí elementos para su cotidianidad, su relación, su sentir y actuar hacia el otro.

Pensar en el bienestar desde una institución que prepara personas para trabajar desde la vida y por la vida, implica orientar su dimensión hacia una humanización de los individuos que están detrás de ésta práctica y se vuelve fundamental llegar a ellos con elementos de valor que crecen desde la familia, la institución educativa, la ciudad y la realidad. Estos elementos se evidencian a través de la comunicación, la tolerancia, el compromiso, el respeto hacia la diversidad, el trabajo en equipo, la sociabilidad $y$ un sin fin de valores que comprometen a cada individuo desde su rol, a asumir su profesión con responsabilidad y sensibilidad social.

De esta forma el bienestar crece bajo los conceptos de formación integral, calidad de vida y construcción de comunidad, aportando escenarios para vivenciar lo humano, lo emocional, lo ético y lo social, complementando así lo académico y lo intelectual. Es decir, que la Fundación Universitaria de Ciencias de la Salud sustenta su finalidad de formar profesionales integrales con el aporte que se hace desde esta unidad, con sus programas, actividades y servicios orientados al desarrollo físico, mental,

Directora de Bienestar Universitario, comunicadora social, Especialización en gerencia de mercadeo. Editorialista invitada. moral, afectivo, social, artístico y cultural de sus estudiantes, docentes y administrativos.

Por esta razón, la Fundación parte de una de una política institucional para cumplir con estos propósitos a través de las áreas de deporte, cultura, salud y desarrollo humano, las cuales se dinamizan desde cada uno de sus campos así:

- Área cultural: busca la formación y apreciación estética y el cultivo de expresiones culturales y artísticas a través del fomento de valores regionales y universales. Se desarrolla mediante líneas de expresión desde lo comunicativo, musical, corporal y artístico.

- Área de deportes: promueve el desarrollo físico y mental a través de un concepto formativo, recreativo y competitivo, con el fin de estimular el desarrollo de aptitudes deportivas y generar estilos de vida saludables.

- Área de promoción del desarrollo humano: busca contribuir con el desarrollo integral de las personas a través de una formación ética para la convivencia, el aprender a vivir juntos, la formación del pensamiento crítico y la conciencia social, mediante el trabajo de valores y el fomento de las relaciones interpersonales propiciadas a través de espacios para compartir, comunicar, disfrutar y celebrar en comunidad. Esta área se apoya en los programas de cultura ciudadana, cultura democrática, el plan de acción social y las celebraciones institucionales. Igualmente promueve una cultura de reconocimiento a través del programa de becas. 
Como evento integrador mayor, la Fundación cuenta con la semana universitaria que se consolida como un espacio de encuentro institucional, en donde se hace evidente el disfrute de la vida universitaria a través de acciones lúdicas, deportivas, recreativas, sociales y culturales, las cuales aportan a la conformación de una comunidad que se dirige en un mismo sentido, hacia la concepción de educar para la vida.
El bien-estar en la Fundación Universitaria, se dinamiza a través de la participación de la comunidad y se hace real, mediante la interacción de todos los estamentos y unidades que entienden que el bienestar es responsabilidad de todos y todos contribuimos desde nuestra acción, en la construcción de una comunidad enfocada hacia el quehacer educativo.

"La primera fuente de bienestar en la Institución es la coherencia entre el discurso, la filosofía de la Institución y la realidad cotidiana" (CESU).

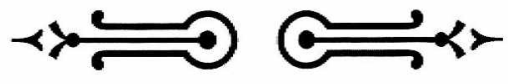

